\title{
Improved harmonic suppression efficiency of single-phase APFs in distorted distribution systems
}

\author{
Samet Biricik \\ Technological University Dublin, samet@biricikelektrik.com \\ Soydan Redif \\ European University of Lefke (Cyprus) \\ Shafiuzzaman Khadem \\ Trinity College Dublin, Ireland
}

See next page for additional authors

Follow this and additional works at: https://arrow.tudublin.ie/engscheleart2

Part of the Electrical and Computer Engineering Commons

\section{Recommended Citation}

Biricik, Samet \& Redif, Soydan \& Khadem, Md. Shafiuzzaman Khan \& Basu, Malabika. (2015). Improved harmonic suppression efficiency of single-phase APFs in distorted distribution systems. International Journal of Electronics. 103. 1-15. 10.1080/00207217.2015.1036318.

This Article is brought to you for free and open access by the School of Electrical and Electronic Engineering at ARROW@TU Dublin. It has been accepted for inclusion in Articles by an authorized administrator of ARROW@TU Dublin. For more information, please contact arrow.admin@tudublin.ie, aisling.coyne@tudublin.ie, gerard.connolly@tudublin.ie.

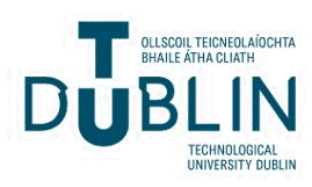




\section{Authors}

Samet Biricik, Soydan Redif, Shafiuzzaman Khadem, and Malabika Basu

This article is available at ARROW@TU Dublin: https://arrow.tudublin.ie/engscheleart2/299 
See discussions, stats, and author profiles for this publication at: https://www.researchgate.net/publication/276534101

\section{Improved harmonic suppression efficiency of single-phase APFs in distorted distribution systems}

Article in International Journal of Electronics · May 2015

DOI: $10.1080 / 00207217.2015 .1036318$

\section{CITATIONS}

16

4 authors:

Samet Biricik

Technological University Dublin - City Campus

62 PUBLICATIONS 714 CITATIONS

SEE PROFILE

(2)

Md. Shafiuzzaman Khan Khadem

Tyndall National Institute

73 PUBLICATIONS 890 CITATIONS

SEE PROFILE
READS

227

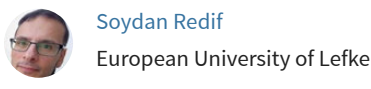

53 PUBLICATIONS 825 CITATIONS

SEE PROFILE

Malabika Basu

Technological University Dublin - City Campus

79 PUBLICATIONS 2,067 CITATIONS

SEE PROFILE

Some of the authors of this publication are also working on these related projects:

Single-ended primary-inductor converters View project

StoreNet View project 


\section{Improved harmonic suppression efficiency of single-phase APFs in distorted distribution systems}

\section{Samet Biricik, Soydan Redif, Shafiuzzaman K. Khadem \& Malabika Basu}

To cite this article: Samet Biricik, Soydan Redif, Shafiuzzaman K. Khadem \& Malabika Basu (2016) Improved harmonic suppression efficiency of single-phase APFs in distorted distribution systems, International Journal of Electronics, 103:2, 232-246, DOI: 10.1080/00207217.2015.1036318

To link to this article: http://dx.doi.org/10.1080/00207217.2015.1036318

Accepted author version posted online: 01

Apr 2015.

Published online: 11 May 2015.

Submit your article to this journal \ulcorner

Џ Article views: 77

Q View related articles $₫$

View Crossmark data $\nearrow$ 


\title{
Improved harmonic suppression efficiency of single-phase APFs in distorted distribution systems
}

\author{
Samet Biricik $^{\mathrm{a}, \mathrm{b} *}$, Soydan Redif ${ }^{\mathrm{b}}$, Shafiuzzaman K. Khadem ${ }^{\mathrm{c}}$ and Malabika Basu ${ }^{\mathrm{a}}$ \\ ${ }^{a}$ School of Electrical \& Electronic Engineering, Dublin Institute of Technology (DIT), Dublin, \\ Ireland; ${ }^{b}$ Department of Electrical \& Electronic Engineering, European University of Lefke, \\ Cyprus, Mersin, 10 Turkey; ${ }^{c}$ Department of Civil, Structural \& Environmental Engineering, Trinity \\ College Dublin (TCD), Dublin, Ireland
}

(Received 1 July 2014; accepted 26 October 2014)

\begin{abstract}
In this study, a control method is proposed to improve the harmonic suppression efficiency of the single-phase active power filter in a distorted power system to suppress current harmonics and reactive power. The proposed method uses the selftuning filter (STF) algorithm to process single-phase grid voltage in order to provide a uniform reference grid current, which increases the efficiency of the system. The results of the simulation study are presented to verify the effectiveness of the proposed control technique in this study.
\end{abstract}

Keywords: single-phase active power filter; self-tuning filter; distorted grid voltage; power quality

\section{Introduction}

In order to determine the harmonic and reactive components of the load current, several control methods are proposed in the literature. These methods applied to active power filters (APFs) play a very important role on the performance and stability of an APF. The self-tuning filter (STF) was originally developed to estimate the phase angle of pulse width modulation (PWM) converter outputs (Song, 2000). It was then applied to solve the control problem of shunt APF in distorted voltage conditions (Ben Habib, Jacquot, \& Saadate, 2003). The STF algorithm was shown to possess important advantages over other methods in the control of three-phase APFs. Since then much attention has been devoted to the application of STF to the control of three-phase APFs (Abdusalam, Poure, Karimia, \& Saadatea, 2009; Abdusalam, Poure, \& Saadate, 2007, 2008, Adam, Stan, \& Livint, 2012; Ahmed, Madjid, Youcef, \& Hamza, 2012; Benaissa, Rabhi, Benkhoris, Moussi, \& Le Claire, 2012; Biricik, Ozerdem, Redif, \& Kmail, 2011, 2012, 2013; Biricik, Redif, Ozerdem, Khadem, \& Basu, 2014; Ghadbane, Ghamri, Benchouia, \& Golea, 2012; Ghamri, Benchouia, \& Golea, 2012; Gupta, Dubey, \& Singh, 2010; Karimi, Poure, \& Saadate, 2008; Mesbahi, Ouari, Abdeslam, Djamah, \& Omeiri, 2014; Ozerdem \& Biricik, 2012; Samadaei, Lesan, \& Cherati, 2011; Samedaei, Vahedi, Sheikholeslami, \& Lesan, 2010). To date, the STF algorithm has only been adapted to the three-phase $p-q$ theory and the $d q$ method, referred to here as the STF-based $p q$ theory (STF-pq) (Abdusalam et al., 2007; Ozerdem \& Biricik, 2012) and STF-based $d q$ method

*Corresponding author. Email: samet@biricikelektrik.com 
$(S T F-d q)$ (Karimi et al., 2008; Mesbahi et al., 2014), respectively. Abdusalam et al. (2007) proposed the integration of the STF algorithm with the $d-q$ theory for the control of hybrid APFs (HAPFs), where a shunt APF was connected in series with a shunt passive filter. Karimi et al. (2008) also showed how the STF can be used to control a shunt APF by integrating it with the $p q$ theory, and referred to the resultant system as selective bandpass filtering. Abdusalam et al. $(2008,2009)$ applied STF-based control with the $p-q$ theory for voltage signals and current signals, without the use of low-pass or high-pass filters. The STF was also used for both voltage and current signals in Abdusalam et al. (2009) and Adam et al. (2012). Gupta et al. (2010) used the STF-pq under the name of harmonic tuned filter. Samadaei et al. (2011) also used STF-pq to control shunt APF connected in series with the shunt passive filter. In Benaissa et al. (2012), the STF-pq theory is used for the first time, in the control of multi-level shunt APFs. Using this method the number of filters is reduced in the control system. However, the effectiveness of the control algorithm is only tested under balanced currents with ideal grid-voltage conditions. Ghadbane et al. (2012) used the STF-pq theory, where the STF is applied to the load current only. The STF was first used to extract harmonic currents from load currents with subsequent application of the $p-q$ theory in Ghamri et al. (2012). In Biricik et al. (2011), it is shown that the harmonic suppression performance of both the $p q$ and $d q$ control methods deteriorates in the case of distorted source voltages. The authors propose applying an $S T F-p q$-based control strategy to improve the harmonic suppression efficiency of an HAPF and solve the problems caused by unbalanced and distorted source voltages as shown in Biricik et al. (2012).

In Biricik et al. (2014) the STF algorithm is used to manage the distorted and unbalanced voltage and current. This method eliminates the need for additional lowpass or high-pass filtering when extracting harmonic components from the fundamental component. Mesbahi et al. (2014) described the design of a direct power control based on the STF algorithm in order to control three-phase APF.

Although the STF algorithm has been used in the past for three-phase systems, in this study, we show how the STF algorithm can be used successfully for the control of the single-phase APF under weak grid-voltage conditions.

\section{Problem statement}

The power circuit of the studied APF is a single-phase H-bridge PWM converter having a dc capacitor, $C_{d c}$. The associated control system regulates the voltage, which is sensed by potential transformer $2\left(\mathrm{PT}_{2}\right)$, on the dc-link capacitor and controls the reference filter current, $i_{c}^{*}$, that compensates the current harmonics. The ac side of the voltage source inverter (VSI) is connected to the common coupling point (PCC) through an inductor, $L_{c}$, and current through the inductor is measured by current transformer $2\left(\mathrm{CT}_{2}\right)$. The non-linear load, which comprises a resistive $\left(R_{L}\right)$ and an inductive $\left(L_{L}\right)$ element, is supplied from a full-bridge rectifier. The consumed load current by the non-linear load is measured using $\mathrm{CT}_{1}$. In this study, the control scheme is based on the load and filter current measurements (Hsu \& Wu, 1996; Khadkikar, Chandra, \& Singh, 2009; Komurcugil \& Kukrer, 2006; Kunjumuhammed \& Mishra, 2006; Mesbahi et al., 2014; Palandöken, Aksoy, \& Tümay, 2003; Torrey \& Al-Zamel, 1995; Tsang \& Chan, 2006), as given in Figure 1.

When the grid voltage is ideal, $u_{s}$ is given by

$$
u_{s}=U_{s} \cdot \sin (\omega t)
$$




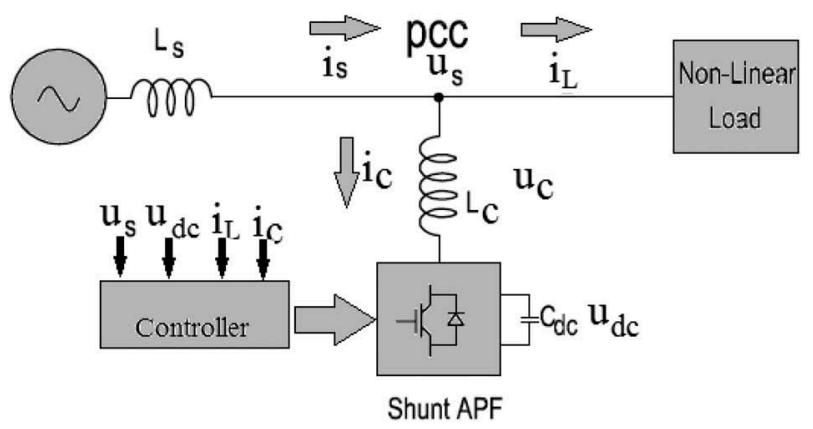

Figure 1. Block diagram of the single-phase APF.

where $U_{s}$ is the amplitude of the grid voltage.

It is well known that single-phase, non-linear loads draw a non-sinusoidal current and can be represented as

$$
i_{L}(t)=\sum_{h=1}^{\infty} i_{L, h} \sin \left(h \omega t+\varnothing_{h}\right)=i_{L, 1} \sin \left(\omega t+\varnothing_{1}\right)+\sum_{h=2}^{\infty} i_{L, h} \sin \left(h \omega t+\emptyset_{h}\right),
$$

where $h$ is the harmonic order, $\varnothing_{h}$ is the harmonic phase angle and $\omega$ is the angular frequency of the fundamental harmonic. As can be seen in Equation (2), the load current, $i_{L}$, consists of a fundamental current, $i_{1}$, and harmonic currents, i.e.

$$
i_{L}=i_{L, 1}+\sum_{h=2}^{\infty} i_{L, h}
$$

The load current, $i_{L}$, used by the control system is measured by $\mathrm{CT}_{2}$. The main aim of the APF is to compensate for all harmonic currents, $i_{h}$, and the reactive current, $i_{q}$, dynamically. Therefore, the VSI is controlled to generate a compensation current, $i_{c}$, which is equal to the harmonics with opposite phase, i.e.

$$
i_{c}=-\underbrace{\left(i_{3}+i_{5}+i_{7}+i_{9}+i_{n}\right)}_{i_{h}}+i_{q} .
$$

This current is required by the control system for injection into the PCC. The current, $i_{c}$, is related to the interfacing inductor voltage, $u_{c}$, which is controlled by the proposed control circuit, by

$$
\frac{d}{d t} i_{c}=\frac{u_{s}-u_{d c}}{L_{c}}
$$

where $u_{d c}$ is the measured voltage on the dc-link capacitor and

$$
u_{c}=u_{s}-u_{d c}
$$

Hence, the compensation current, $i_{c}$, can be obtained thus 


$$
i_{c}=\frac{1}{L_{c}} \int\left(u_{s}-u_{d c}\right) d t
$$

As can be seen, the compensation current $i_{c}$ can be generated in the circuit by controlling voltages on the inductor terminals. Therefore, the related control circuit should first calculate the reference grid compensation current, $i_{s}^{*}$, then the required reference compensation current, $i_{c}^{*}$, can be determined by subtracting it from the measured load current, $i_{L}$, i.e.

$$
i_{c}^{*}=i_{s}^{*}-i_{L}
$$

It is evident that the main issue is the determination of the grid reference current, $i_{s}^{*}$, since the decision from the control circuit mainly depends on this calculation. For this reason, the pre-settled dc-link capacitor voltage, $u_{d c}^{*}$, is subtracted from the actual measured dclink capacitor voltage, $u_{d c}$, to obtain instantaneous error, $\Delta u_{d c}$, as

$$
\Delta u_{d c}=u_{d c}-u_{d c}^{*}
$$

Then this instantaneous error, $\Delta u_{d c}$, is evaluated using a proportional integral (PI) regulator to compute the amplitude of the grid current; thus

$$
I_{s}=k_{p} \Delta u_{d c}+k_{i} \int \Delta u_{d c} d t
$$

where $k_{p}$ and $k_{i}$ are the proportional and integral gains of the dc-link PI regulator, which is found the usual way. The reference grid current, $i_{s}^{*}$, can be obtained by multiplying the magnitude of the grid current, $I_{s}$, with $\sin (\omega t)$ (unity sine function). Since the grid current and grid voltage need to be in phase, the generation of the unity sine function using the measured grid voltage $\left(U_{s} \cdot \sin (\omega t)\right)$, is a viable solution, as in Equation (11) (Komurcugil \& Kukrer, 2006; Tsang \& Chan, 2006). The unity sine function is given by

$$
u_{s}^{\prime}=\frac{1}{U_{s}}\left[U_{s} \cdot \sin (\omega t)\right]
$$

where $U_{s}$ is the amplitude of the grid voltage.

However, the result in Equation (11) will be difficult to obtain when grid voltages are distorted, i.e. contain harmonics, as will be shown in Section 4. Under such conditions, the pure sinusoid in Equation (11) cannot be obtained correctly, causing degradation in the system performance. As a consequence, it may not be possible to reduce the grid-current total harmonic distortion (THD) to less than 5\%, as specified in IEEE 519-1992.

\section{Proposed control method}

To date, the STF has only been applied to three-phase APF systems in an effort to combat the effects of non-ideal grid voltages (Abdusalam et al., 2009; Biricik et al., 2014; Ghamri et al., 2012; Mesbahi et al., 2014). The STF transfer function is obtained from the integration of the synchronous reference (Abdusalam et al., 2009), and is defined as 


$$
H(s)=\frac{V_{x y}(s)}{U_{x y}(s)}=\frac{s+j \omega}{s^{2}+\omega^{2}},
$$

where $V_{x y}(s)$ and $U_{x y}(s)$ are the input and output signals of the STF algorithm, respectively. Using the inverse Laplace transform, it can be shown that the impulse response of the STF is

$$
h(t)=\cos \omega t+j \sin \omega t=e^{j \omega t}
$$

From this we see that the STF is a filter with complex coefficients, describing a complex sinusoid. Given a cosine function on one of the inputs and a sine function on the other input, it adaptively seeks to generate a complex sinusoid. The feedback elements of the STF give it a degree of freedom in order to adaptively construct the complex sinusoid while suppressing the effects of any unwanted signals. The STF can also be viewed as a matched filter, which is 'matched' to the linear combination of the in-phase and quadrature-phase components of the complex sinusoid. That is, it is an adaptive matched filter to pure tones separated in phase by $90^{\circ}$. For the three-phase power system, the in-phase and quadrature-phase components, $u_{\alpha}$ and $u_{\beta}$, respectively, are made available via the Clark (or Park) transform. These signals are naturally $90^{\circ}$ apart in phase, as required by the STF in order to synthesise the complex sinusoid. Equivalently, the STF adaptively matches to the linear combination of the two sinusoidal components, $u_{\alpha}$ and $u_{\beta}$, while suppressing unwanted signals, such as harmonics.

However, in the case of the single-phase system, there is only one sinusoidal input, and so there is no notion of the in-phase and quadrature-phase components. In order to successfully apply the STF, there is a requirement for a second signal that is $90^{\circ}$ out of phase with the single-phase input signal. This will allow the STF to generate (or match to) the complex sinusoid. For example, consider that the single-phase input signal (measured line voltage) is a sine function, $u_{\alpha}(t)=\sin \omega t$. Then a quadrature-phase component can be synthesised for the STF by phase-shifting $u_{\alpha}(t)$ by $90^{\circ}$, i.e.

$$
u_{\beta}(t)=\sin \left(\omega t+\frac{\pi}{2}\right)=\cos \omega t
$$

Note that the signal $u_{\beta}(t)$ can be obtained, e.g. using the Hilbert transform. Also, note that in order to have unit magnitude, i.e. $|H(s)|=0 \mathrm{~dB}$, a constant $K$ is incorporated into Equation (12), i.e.

$$
H(s)=\frac{V_{x y}(s)}{U_{x y}(s)}=K \frac{(s+K)+j \omega}{(s+K)^{2}+\omega^{2}} .
$$

The undistorted two-phase voltages $\left(\bar{u}_{\alpha}, \bar{u}_{\beta}\right)$ can be obtained by processing the distorted grid voltages $\left(u_{\alpha}, u_{\beta}\right)$ with the STF algorithm; thus

$$
\bar{u}_{\alpha}(s)=\frac{K}{s}\left[u_{\alpha}(s)-\bar{u}_{\alpha}(s)\right]-\frac{\omega}{s} \bar{u}_{\beta}(s)
$$

and 


$$
\bar{u}_{\beta}(s)=\frac{K}{s}\left[u_{\beta}(s)-\bar{u}_{\beta}(s)\right]+\frac{\omega}{s} \bar{u}_{\alpha}(s) .
$$

The obtained $\bar{u}_{\alpha}$ can be considered as the filtered grid voltage, i.e.

$$
\bar{u}_{s}=\bar{u}_{\alpha}
$$

where $\bar{u}_{\alpha}$ is obtained by Equation (16). Finally, the correct unity sine function can be determined by dividing $\bar{u}_{s}$ with the amplitude of the grid voltage. The amplitude of the grid voltage may be considered as constant since it is known. However, in this case, the control method can be affected even by small voltage fluctuations. The most preferred method is using a peak detector, or by multiplying the measured $r m s$ grid voltage with $\sqrt{2}$. Then the reference grid current, $i_{s}^{*}$, can be calculated by multiplying the amplitude of the grid current, $I_{s}$, with the unity sine function (Hsu \& Wu, 1996; Komurcugil \& Kukrer, 2006; Palandöken et al., 2003; Tsang \& Chan, 2006), i.e.

$$
i_{s}^{*}=I_{s} \sin (\omega t)
$$

Once the target reference grid current waveform is determined, the reference compensation current, $i_{c}^{*}$, can be obtained correctly, as given in Equation (8). Then the compensation current error, $\Delta i_{c}$, can be obtained by subtracting $i_{c}^{*}$ from the measured compensation current, $i_{c}$; thus

$$
\Delta i_{c}=i_{c}^{*}-i_{c}
$$

where the compensation current error is used to drive the VSI switches $\left(\mathrm{S}_{1}, \mathrm{~S}_{2}, \mathrm{~S}_{3}\right.$ and $\left.\mathrm{S}_{4}\right)$. The actual compensating current, $i_{c}$, at the PCC can be controlled by a hysteresis current controller, which has been widely used for active filter applications because of its simple structure. The controller aims to keep the controlled current inside a defined region around the desired reference current by tracing the desired reference current, $i_{c}^{*}$. The overall system of the studied topology and proposed control method is given in Figure 2.

\section{Design of the proposed single-phase APF circuit parameters}

In this subsection, the operation principle and design concept of the proposed single-phase APF is studied in detail. In particular, we present the design of the proposed converter, the converter coupling inductances and the dc-link capacitor.

\subsection{Determination of the dc-link capacitor voltage $\left(u_{d c}\right)$}

The purpose of the dc-link capacitor $\left(C_{d c}\right)$ is threefold: (1) to maintain the $u_{d c}$ with minimal ripple in steady state, (2) to serve as an energy storage element to supply the reactive/harmonic power of the load and (3) to supply the real power difference between the load and source during the transient period (Khadem, Basu, \& Conlon, 2014). Therefore, the size of $C_{d c}$ should be selected, and the controller should be designed in such a way that the APF can compensate for the real power difference, for a short transient period (typically a number of $\mathrm{ms}$ ), after which the controller should be able to adjust the reference current. Thus the rating $u_{d c}$ can be maintained at a reference value. The capacitor voltage rating selection is made according to the peak value of the grid voltage. In order to transfer the capacitor current to the load, the capacitor voltage must be 


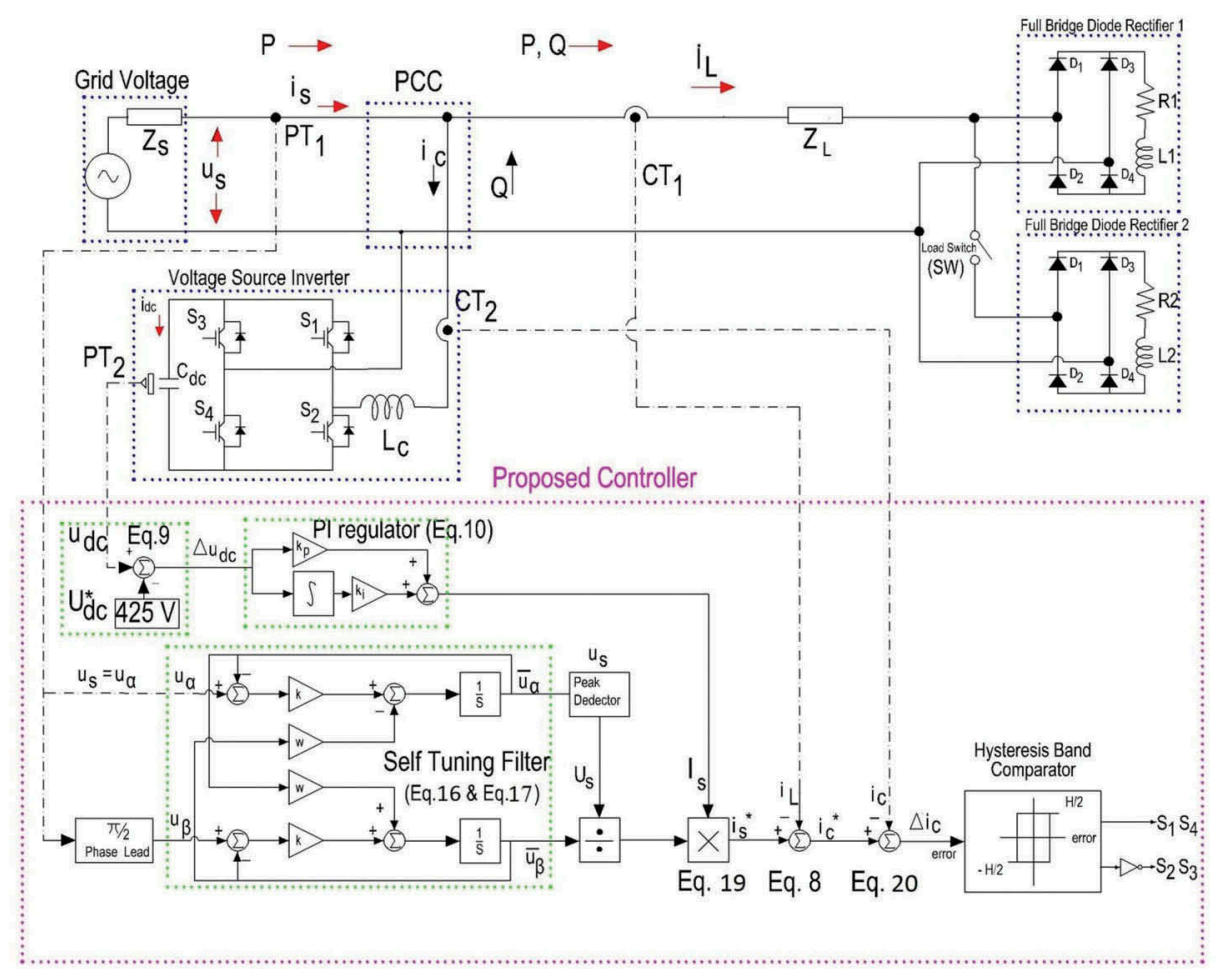

Figure 2. Block diagram of the proposed single-phase APF.

chosen higher than the peak value of the grid voltage; however, it should also be limited because a high voltage ratio can increase the switching losses on the converter. Moreover, if the dc-link capacitance is not sufficiently high, the filter inductor current cannot change smoothly. Also, if the capacitance is greater than is necessary, the dynamic response of the system reduces. According to Biricik (2013), the minimum voltage ratio of the dc-link capacitor can be determined as follows:

The maximum dc-link voltage of the single-phase converter can be determined as

$$
u_{d c(\max )}=1.5 \sqrt{2} u_{s}
$$

The minimum voltage ratio of the dc-link capacitor can be determined as follows:

$$
u_{d c(\min )}=\sqrt{2} u_{s}
$$

Therefore, the required dc-link voltage for the single-phase APF is

$$
\mathrm{u}_{\mathrm{dc}}^{*}=\frac{\mathrm{u}_{\mathrm{dc}(\max )}+\mathrm{u}_{\mathrm{dc}(\min )}}{2},
$$

where $\mathrm{u}_{\mathrm{dc}(\min )}$ is the minimum and $\mathrm{u}_{\mathrm{dc}(\max )}$ is the maximum dc-link voltage. Finally Equation (23) can be simplified as 


$$
u_{d c}=1.25 \sqrt{2} u_{s}
$$

\subsection{Design of dc-link capacitance value $\left(C_{d c}\right)$}

The main aim of the dc-link capacitor is to absorb or supply real power demand of the load during transience (Singh, Singh, \& Mitra, 2007). In Benchaita, Saadate, and Salem (1999) the following method is proposed to determine the dc-link capacitor value:

$$
C_{d c}=\frac{\tilde{p}}{2 \pi f \cdot u_{d c} \cdot \Delta u_{d c}}
$$

where $u_{d c}$ is the voltage across the dc-link capacitor, $\tilde{p}$ is the harmonic power to be generated by the converter and $\Delta u_{d c}$ is acceptable dc voltage ripple. Alternatively, the method proposed by Chatterjee et al. (1999) can be used to obtain the value of the dc-link capacitor. This method is based on the maximum active power rating of the load. Therefore, during the peak power of the load, the maximum energy demanded from the dc-link capacitor for the worst case in transient behaviour should be calculated. This energy is given by

$$
E_{\max }=P_{\max } .20 \times 10^{-3} \mathrm{~J}
$$

and the minimum dc-link voltage is

$$
E_{\text {max }}=\frac{1}{2} C_{d c} u_{d c}^{2}-\frac{1}{2} C_{d c} u_{d c(\min )}^{2} .
$$

Finally, the size of the dc-link capacitor is obtained as follows:

$$
C_{d c}=\frac{2 P_{\max } \cdot 20 \times 10^{-3}}{u_{d c}^{2}\left[1-\left(\frac{\mathrm{u}_{\mathrm{dc}(\min )}}{\mathrm{u}_{\mathrm{dc}}}\right)^{2}\right]} .
$$

The correct method for calculating $C_{d c}$ largely depends on the condition of operation. The first method in Equation (25) gives the optimum capacitor value if the maximum harmonic power is known, and therefore cannot be relied upon when the characteristics of the load groups are not known well. The second method, as given in Equation (28), is based on the total active power of the load groups. This method can be useful when harmonic analysis of the system is not practical, such as when the load groups are highly variable. For the system under consideration, the first method, i.e. Equation (25), is adopted, since harmonic analysis of our system can be achieved.

\subsection{Design of interfacing inductor $\left(L_{c}\right)$}

In single- or three-phase full-bridge systems, the filter is based on the single- or threephase full-bridge topology, and compensates for the harmonic current by way of a hysteresis (current) controller. In this case, the value of $L_{c}$ can be calculated as follows (Khadem et al., 2014): 


$$
L_{c}=\frac{u_{c}(0)}{4 h f_{\text {swmax }}}=\frac{u_{d c}}{4 h f_{\text {swmax }}},
$$

where $f_{\text {swmax }}$ is the considered maximum switching frequency for the insulated-gate bipolar transistor of the hysteresis controller and $h$ is the hysteresis band, which is usually taken as

$$
h=(0.05 \text { to } 0.15) I_{c}
$$

\section{Simulation results}

The proposed control method is simulated using MATLAB/Simulink along with the power system block set for performance verification purposes. Two variable RL (resistive and inductive)-type non-linear loads (Load 1 and Load 2) are used to observe dynamic performances of the single-phase APF. The parameter values used in this work are given in Table 1.

Simulation results have shown that the distorted grid voltage has a THD of $18.5 \%$ (see Figure 4). The THD of the load current (Load 1) is $29.96 \%$, while the rms current is $10.04 \mathrm{~A}$; when both loads (Load 1 and Load 2) are connected to the grid, the THD increases to $25.54 \%$ with an rms current of $17.35 \mathrm{~A}$. The grid voltage and load current waveforms are shown in Figure 3 (a). In Figure 3 (b), it can be seen that the grid voltage is not sinusoidal; correspondingly, the two-phase versions, $\alpha$ and $\beta$, obtained in Section III, are also non sinusoidal - see Figure 3 (c). From Figure 3 (d), we can see that, as expected, the filtered two-phase voltages, $\left(\bar{u}_{\alpha}, \bar{u}_{\beta}\right)$, are sinusoidal. The quantity $\bar{u}_{\alpha}$, obtained by way of Equation (16), is the filtered grid voltage, and is shown in Figure 3 (e) along with the voltage amplitude, $U_{s}$. In Figure 3 (f), we can see that the unit amplitude sine function has been successfully generated. In Figure $3(\mathrm{~g})$, it is evident that the dc-link capacitor voltage is maintained, as required during the load change. Finally, the injected converter current can be seen in Figure 3 (h) and the resulting grid current waveforms are presented in Figure 3 (j). As a result of this, the THD of the grid current is reduced to $3.77 \%$ in the first load combination (see Figure 5(a)) and it is reduced to $3.57 \%$ in the second load combination (see Figure 5(b)), which meets the IEEE 519-1992 recommended standard.

Table 1. Parameters of the analysed system.

\begin{tabular}{lll}
\hline Symbol & \multicolumn{1}{c}{ Quantity } & \multicolumn{1}{c}{ Value } \\
\hline $\mathrm{u}_{\mathrm{S},} f$ & Line to Neutral Volt. \& Freq. & $240 \mathrm{~V}, 50 \mathrm{~Hz}$ \\
$\mathrm{Z}_{\mathrm{s}}$ & Grid Impedance & $1 \mathrm{~m} \Omega, 0.7 \mathrm{mH}$ \\
$\mathrm{Z}_{\mathrm{c}}$ & Converter Impedance & $1 \mathrm{~m} \Omega, 16 \mathrm{mH}$ \\
$\mathrm{Z}_{\mathrm{L}}$ & Load Impedance & $1 \mathrm{~m} \Omega, 6.8 \mathrm{mH}$ \\
Load 1 & Non-Linear Load Res. and Ind. & $30 \Omega, 80 \mathrm{mH}$ \\
Load 2 & Non-Linear Load Res. and Ind. & $40 \Omega, 80 \mathrm{mH}$ \\
$\mathrm{C}_{\mathrm{dc}}$ & APF dc Capacitor & $800 \mu \mathrm{f}$ \\
$\mathrm{U}_{\mathrm{dc}}$ & dc-link reference voltage & $425 \mathrm{~V}$ \\
$\mathrm{~K}_{\mathrm{p}} \& \mathrm{~K}_{\mathrm{i}}$ & Proportional \& Integral Gain & $0.03 \& 2.9$ \\
$\mathrm{~K}$ & STF Gain & 50 \\
$\mathrm{Ts}$ & Sample Time & $25 \mu \mathrm{S}$ \\
\hline
\end{tabular}




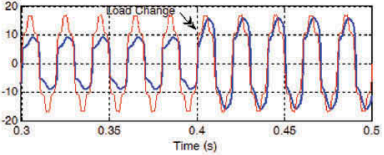

(a)

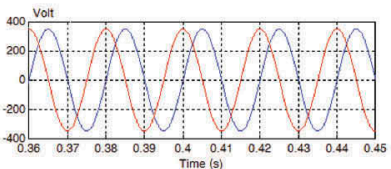

(d)

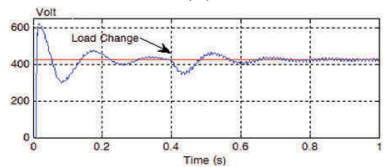

(g)

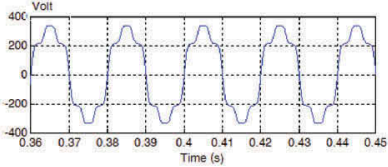

(b)

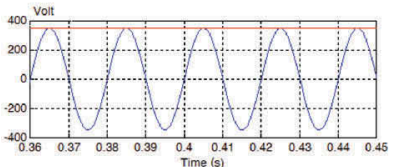

(e)

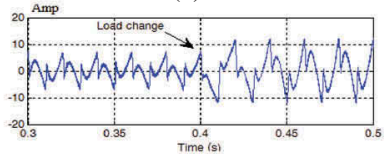

(h)

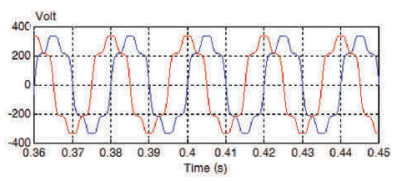

(c)

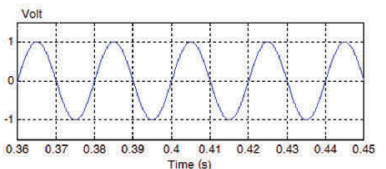

(f)

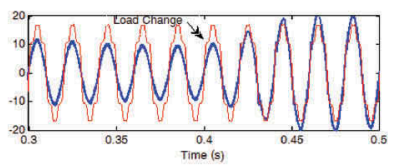

(j)

Figure 3. (a) Grid voltage, $\mathrm{u}_{\mathrm{s}}$, and distorted load current, $\mathrm{i}_{\mathrm{L}}$; (b) distorted grid voltage, $\mathrm{u}_{\mathrm{s}}$, (c) $\alpha-$ and $\beta$-axis grid voltages, $\left(u_{\alpha}, u_{\beta}\right)$; (d) STF output signal $\left(\bar{u}_{\alpha}, \bar{u}_{\beta}\right)$; (e) the obtained undistorted voltage signal, $\bar{u}_{s}$, and the magnitude of the source voltage, $U_{s}$; (f) unity sine function; (g) dc-link voltage; (h) converter current, $i_{c}$; and (j) grid voltage, $\mathrm{u}_{\mathrm{s}}$, and source current, $i_{s}$.

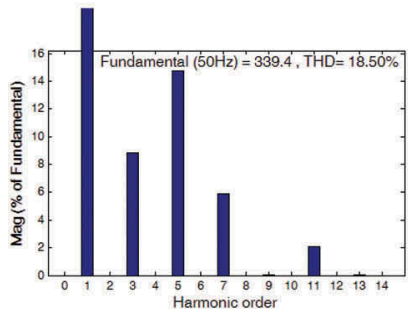

(a)

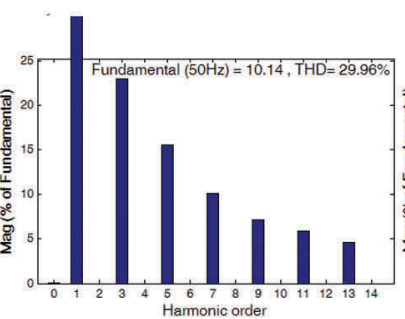

(b)

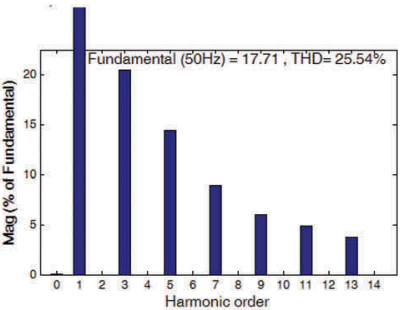

(c)

Figure 4. Fast Fourier transform (FFT) analysis (a) grid voltage, (b) load 1, (c) Load 1 and Load 2.

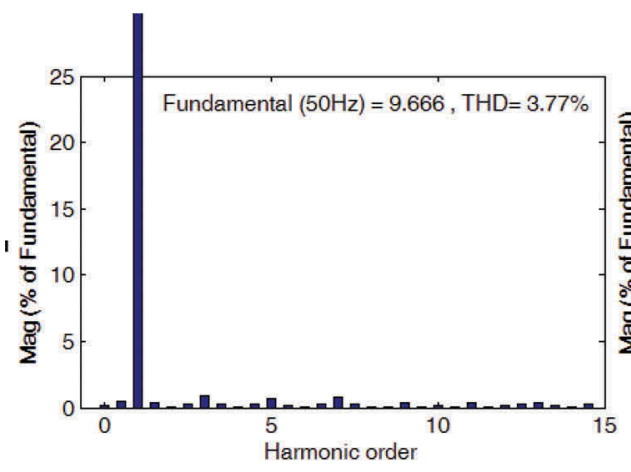

(a)

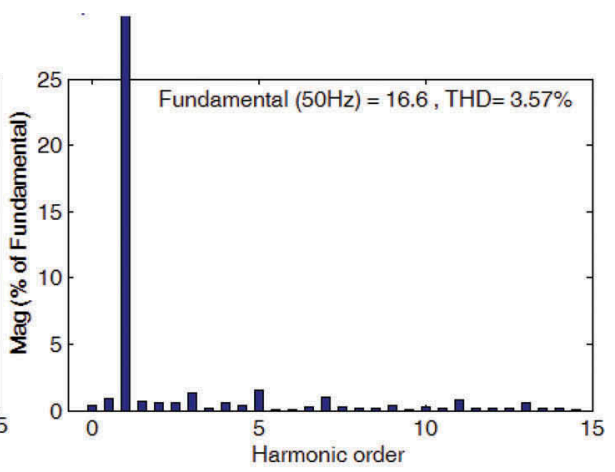

(b)

Figure 5. Grid current FFT analysis during operation of (a) load 1, (b) loads 1 and 2. 


\section{Real-time control in software-in-the-loop (SIL) configuration}

The proposed system and power system have been verified using RT-LAB real-time platform and associated tools to observe the performance in a real-time environment. RT-LAB (v10.5.7.344) allows for the distributed tests of complex power systems using the OPALRT (OP5600) platform, which manages the communications between the CPUs, FPGA architecture and the console PC (from which the global simulation is controlled). Specifically, the proposed system is realised on a field programmable gate array (FPGA) architecture using the Xilinx system generator toolbox to demonstrate the performance of the proposed control method, and results from real-time experimentation are presented in this section. In particular, the effect of non-ideal supply conditions on the performance of APF is investigated. The system parameters used in the experiments are given in Table 1. In order to demonstrate the performance of the proposed control method, the real-time experimental results are compared with a state-of-the-art technique described in Hsu and Wu (1996), Khadkikar et al. (2009), Komurcugil and Kukrer (2006), Kunjumuhammed and Mishra (2006), Palandöken et al. (2003), Torrey and Al-Zamel (1995) and Tsang and Chan (2006).

\subsection{Analysis of the state of the art}

In this subsection, we first evaluate the performance of the single-phase APF using the sine multiplication theorem (Hsu \& Wu, 1996; Khadkikar et al., 2009; Komurcugil \& Kukrer, 2006; Kunjumuhammed \& Mishra, 2006; Palandöken et al., 2003; Torrey \& AlZamel, 1995; Tsang \& Chan, 2006), under ideal grid-voltage conditions. It is important to note that the common point of this study is the determination of the grid current, $i_{s}^{*}$.

However, the method for determining the amplitude of the grid current may differ from system to system. As can be seen in Figure 6 (a), the grid current is adequately compensated for using the sine multiplication method, as reported in Hsu and Wu (1996), Komurcugil and Kukrer (2006), Palandöken et al. (2003) and Tsang and Chan (2006). Moreover, the effect of the reactive power consumed by the load groups is compensated effectively, as seen in Figure 6 (b).

To show the effects of the non-ideal grid voltage on the performance of the single-phase APF, voltage distortion is considered, as shown in Figure 6 (c), where channel 4 has a THD of $10 \%$. The load current waveforms under non-ideal grid-voltage conditions are shown in Figure 6 (a) - channel 1. As can be seen, the THD of the grid current could not be reduced sufficiently (see Figures 6 (d) and 7). It is clear that the non-ideal supply condition adversely affects the behaviour of the APF while using the conventional method. This is mainly because of the sine function determination method. Note the required reference grid current and amplitude are determined using the method described in Section 2.

\subsection{Analysis of the proposed method}

The mentioned negative situation in Section 5.1 is rectified using the STF algorithm for the single-phase system described in Section 3, and the proposed method is verified experimentally in this subsection.

As discussed in Section 2, first the grid voltage is converted to the two-phase coordinate system. In order to obtain these conditions in the single-phase system, the measured single-phase grid voltage is considered as quantities on the $\alpha$-axis, and the $\beta$-axis is obtained by $\pi / 2$ leading to grid voltage. As can be seen in Figure 8 (a), the THD of the grid current is reduced to around 3\%. Figure 8 (b) shows that the grid current is in phase with the grid voltage. As seen in Figure 9, the THD of the grid current is reduced considerably. 


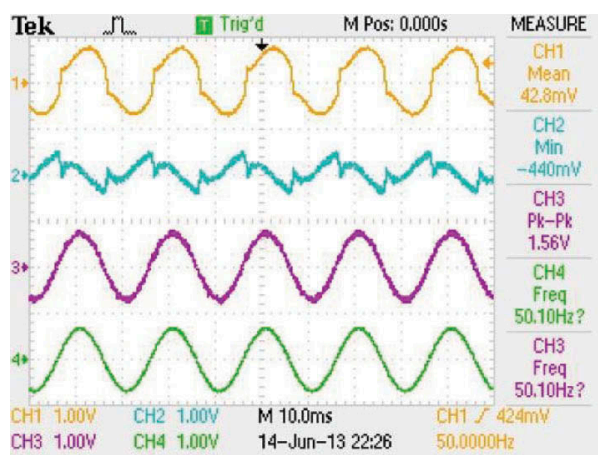

(a)

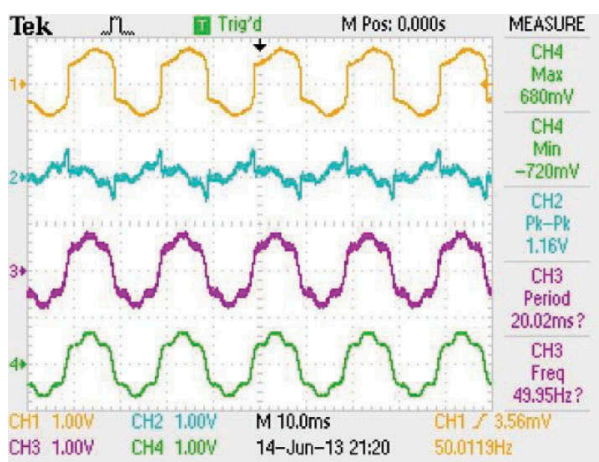

(c)

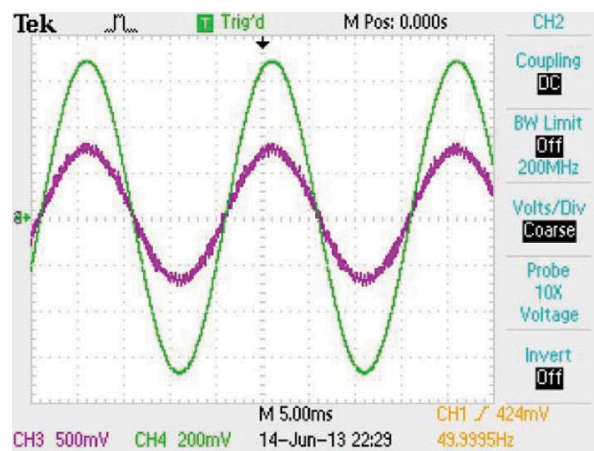

(b)

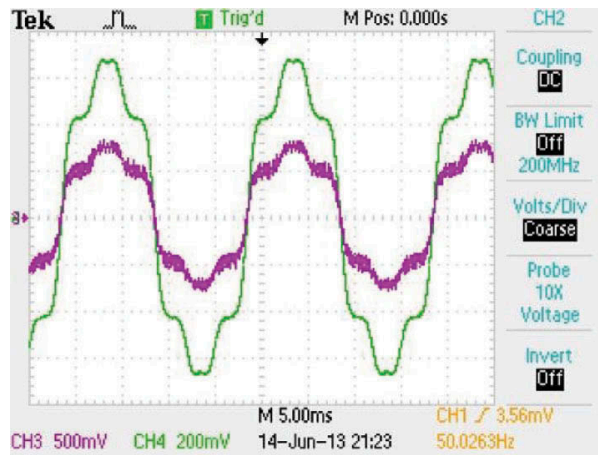

(d)

Figure 6. (a) (CH1) load current, $i_{\mathrm{L}},(\mathrm{CH} 2)$ compensation current, $\mathrm{i}_{\mathrm{c}},(\mathrm{CH} 3)$ grid current, $\mathrm{i}_{\mathrm{s}}$, and (CH4) source voltage, $u_{s}$; (b) grid voltage, $u_{s}$, and grid current, $i_{s}$, under ideal grid-voltage condition; (c) (CH1) load current, $\mathrm{i}_{\mathrm{L}},(\mathrm{CH} 2)$ compensation current, $\mathrm{i}_{\mathrm{c}},(\mathrm{CH} 3)$ grid current, $\mathrm{i}_{\mathrm{s}}$, and (CH4) source voltage, $u_{s}$; (d) grid voltage, $u_{s}$, and grid current, $i_{s}$, under non-ideal grid-voltage condition.

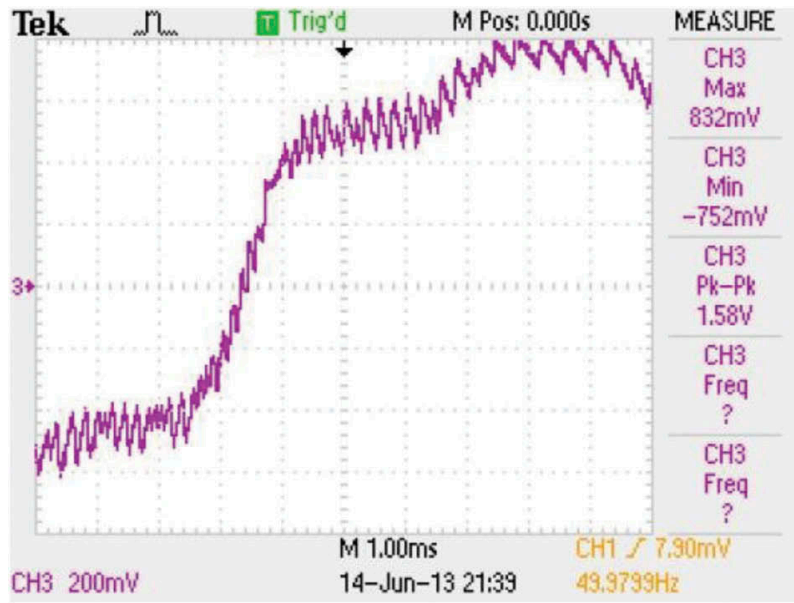

Figure 7. Section of the grid current waveform. 


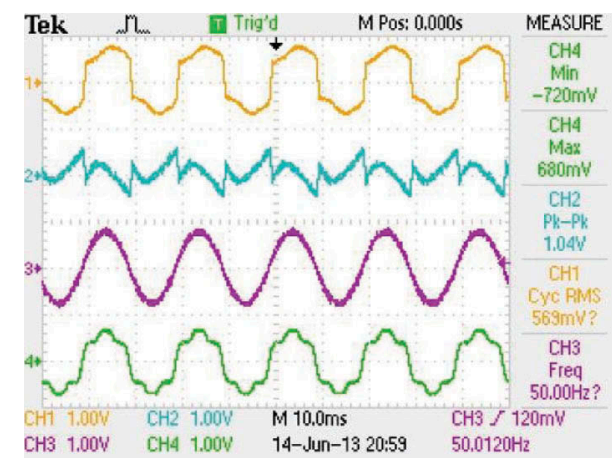

(a)

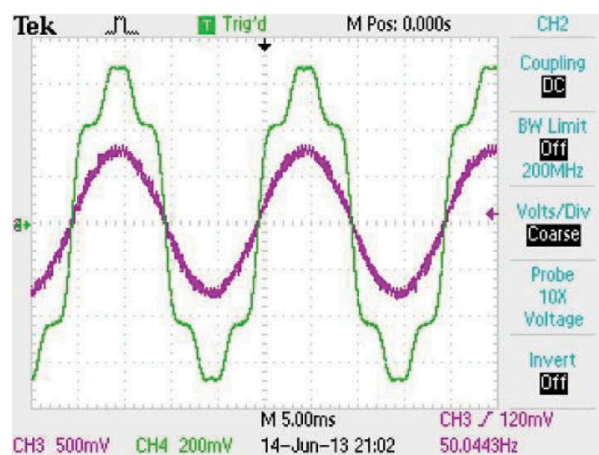

(b)

Figure 8. (a) (CH1) load current, $i_{L}$, (CH2) compensation current, $i_{c}$, (CH3) grid current, $i_{s}$, and (CH4) source voltage, $u_{s}$; (b) grid voltage, $u_{s}$, and grid current, $i_{s}$, under ideal grid-voltage condition.

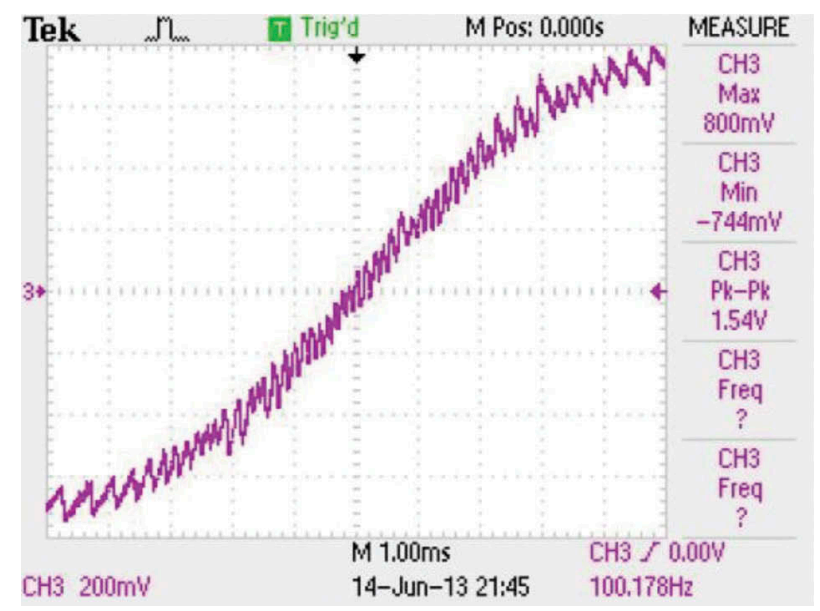

Figure 9. Section of the grid current waveform.

\section{Conclusion}

In this paper, we show a method that uses the STF algorithm for the effective control of the single-phase APF under the case of non-ideal grid-voltage conditions. The STF algorithm has been adapted for application to the problem of controlling a single-phase shunt APF. This was achieved by imposing a $\pi / 2$ phase shift to the measured grid voltage in order to obtain a second-phase function. Results reveal that the shunt APF successfully reduces the grid current harmonics to around 3\% for the case of distorted grid voltages, achieving a THD of $18.5 \%$. The results from real-time experiment verify the effectiveness of the proposed control technique in this study.

\section{Disclosure statement}

No potential conflict of interest was reported by the authors. 


\section{References}

Abdusalam, M., Poure, P., Karimia, S., \& Saadatea, S. (2009). New digital reference current generation for shunt active power filter under distorted voltage conditions. Electric Power Systems Research, 79, 759-776. doi:10.1016/j.epsr.2008.10.009

Abdusalam, M., Poure, P., \& Saadate, S. (2007, April 12-14). A new control scheme of hybrid active filter using self-tuning-filter. International conference on power engineering, energy and electrical drives, POWERENG 2007, Setubal (pp. 35-40). IEEE. doi:10.1109/ POWERENG.2007.4380095

Abdusalam, M., Poure, P., \& Saadate, S. (2008, June 15-19). Hardware implementation of a threephase active filter system with harmonic isolation based on self-tuning-filter. Power electronics specialists conference, IEEE-PESC 2008, Rhodes (pp. 2875-2881). IEEE. doi:10.1109/ PESC.2008.4592385

Adam, G., Stan, A. G., \& Livint, G. (2012, October 25-27). An adaptive hysteresis band current control for three phase shunt active power filter using fuzzy logic. 2012 international conference and exposition on Electrical and Power Engineering (EPE), Iasi (pp. 324-329). IEEE. doi:10.1109/ICEPE.2012.6463910

Ahmed, S., Madjid, G., Youcef, M., \& Hamza, T. (2012, December). Real time control of an active power filter under distorted voltage condition. International Journal of Power Electronics and Drive System, 2(4), 424-433.

Ben Habib, M. C., Jacquot, E., \& Saadate, S. (2003, April 9-11). An advanced control approach for a shunt active power filter. International conference on renewable energies and power quality (Icrepq'03), Vigo.

Benaissa, A., Rabhi, B., Benkhoris, M. F., Moussi, A., \& Le Claire, J. (2012, October 25-28). Fuzzy logic controller for five-level shunt active power filter under distorted voltage conditions. 38th annual conference on IEEE Industrial Electronics Society IECON 2012, Montreal (pp. 49734978). IEEE. doi:10.1109/IECON.2012.6388986

Benchaita, L., Saadate, S., \& Salem, A. (1999, May). A comparison of voltage source and current source shunt active filter by simulation and experimentation. IEEE Transactions on Power Systems, 14(2), 642-647. doi:10.1109/59.761892

Biricik, S. (2013, April). Hybrid active power filter topology for harmonic current suppression and reactive power compensation ( $\mathrm{PhD}$ thesis). Near East University, North Cyprus.

Biricik, S., Ozerdem, O. C., Redif, S., \& Kmail, M. O. I. (2011, December 1-4). Performance improvement of active power filters based on $p-q$ and $d-q$ control methods under non-ideal supply voltage conditions. 7th international conference on electrical and electronics engineering (ELECO 2011), Bursa.

Biricik, S., Ozerdem, O. C., Redif, S., \& Kmail, M. O. I. (2012, March 25-28). Novel hybrid active power filter structure to compensate harmonic currents and reactive power. 16th IEEE mediterranean electro-technical conference - MELECON 2012, Tunisia.

Biricik, S., Ozerdem, O. C., Redif, S., \& Kmail, M. O. I. (2013). Performance improvement of active power filter under distorted and unbalanced grid voltage conditions. Journal of Electronics and Electrical Engineering (Elektronika ir Elektrotechnika), 19(1), 35-39. ISSN $1392-1215$.

Biricik, S., Redif, S., Ozerdem, O. C., Khadem, S. K., \& Basu, M. (2014). Real-time control of shunt active power filter under distorted grid voltage and unbalanced load condition using selftuning filter. IET Power Electronics, Galway. IEEE. doi:10.1049/iet-pel.2013.0924.

Chatterjee, K., Fernandes, B. G., \& Dubey, G. K. (1999, March). An instantaneous reactive voltampere compensator and harmonic suppressor system. IEEE Transactions on Power Electronics, 14(2), 381-392. doi:10.1109/63.750192

Ghadbane, I., Ghamri, A., Benchouia, M. T., \& Golea, A. (2012, December 6-8). Three-phase shunt active power filter for power improvement quality using sliding mode controller. 2nd international conference on communications, computing and control applications (CCCA), Marseilles (pp. 1-6). IEEE. doi:10.1109/CCCA.2012.6417876

Ghamri, A., Benchouia, M. T., \& Golea, A. (2012, January). Sliding-mode control based three-phase shunt active power filter: Simulation and experimentation. Electric Power Components and Systems, 40(4), 383-398. doi:10.1080/15325008.2011.639127

Gupta, N., Dubey, S. P., \& Singh, S. P. (2010, December 20-23). PIL based control algorithm for three-phase four-wire active filter for reactive and harmonic compensation under distorted 
supply. 2010 joint international conference on power electronics, drives and energy systems (PEDES) \& 2010, New Delhi (pp. 1-6). IEEE. doi:10.1109/PEDES.2010.5712501

Hsu, C. Y., \& Wu, H. Y. (1996, January). A new single-phase active power filter with reduced energy-storage capacity. IEE Proceedings Electric Power Applications, 143(1), 25-30.

Karimi, S., Poure, P., \& Saadate, S. (2008, June 15-19). High performances reference current generation for shunt active filter under distorted and unbalanced conditions. IEEE-PESC, Rhodes (pp. 195-201). IEEE. doi:10.1109/PESC.2008.4591924

Khadem, S. K., Basu, M., \& Conlon, M. F. (2014, February). Harmonic power compensation capacity of shunt active power filter and its relationship with design parameters. IET Power Electronics, 7(2), 418-430. doi:10.1049/iet-pel.2013.0098

Khadkikar, V., Chandra, A., \& Singh, B. N. (2009, January). Generalised single-phase p-q theory for active power filtering: Simulation and DSP-based experimental investigation. IET Power Electronics, 2(1), 67-78. doi:10.1049/iet-pel:20070375

Komurcugil, H., \& Kukrer, O. (2006, February). A new control strategy for single-phase shunt active power filters using a Lyapunov function. IEEE Transactions on Industrial Electronics, 53(1), 305-312. doi:10.1109/TIE.2005.862218

Kunjumuhammed, L. P., \& Mishra, M. K. (2006, May). A control algorithm for single-phase active power filter under non-stiff voltage source. IEEE Transactions on Power Electronics, 21(3), 822-825. doi:10.1109/TPEL.2006.874939

Mesbahi, N., Ouari, A., Abdeslam, D. O., Djamah, T., \& Omeiri, A. (2014). Direct power control of shunt active filter using high selectivity filter (hsf) under distorted or unbalanced conditions. Electric Power Systems Research, 108, 113-123. doi:10.1016/j.epsr.2013.11.006

Ozerdem, O. C., \& Biricik, S. (2012, November 29-December 1). Control of shunt active filter under non-ideal grid voltage and un-balanced load conditions. Electrical, Electronics and Computer Engineering (ELECO 2012). Bursa (in Turkish).

Palandöken, M., Aksoy, M., \& Tümay, M. (2003). A fuzzy-controlled single-phase active power filter operating with fixed switching frequency for reactive power and current harmonics compensation. Electrical Engineering, 86(1), 9-16. doi:10.1007/s00202-003-0183-5

Samadaei, E., Lesan, S., \& Cherati, S. M. (2011, April 18-19). A new schematic for hybrid active power filter controller. 2011 IEEE Applied Power Electronics Colloquium (IAPEC), Johor Bahru (pp. 143-148). IEEE. doi:10.1109/IAPEC.2011.5779850

Samedaei, E., Vahedi, H., Sheikholeslami, A., \& Lesan, S., (2010, September 14-15). Using STF$P Q$ algorithm and hysteresis current control in hybrid active power filter to eliminate source current harmonic. Power quality conference, Tehran.

Singh, G. K., Singh, A. K., \& Mitra, R. (2007). A simple fuzzy logic based robust active power filter for harmonics minimization under random load variation. Electric Power Systems Research, 77, 1101-1111. doi:10.1016/j.epsr.2006.09.006

Song, H. S. (2000). Control scheme for pwm converter and phase angle estimation algorithm under voltage unbalance and/or sag condition ( $\mathrm{PhD}$ thesis in electronic and electrical engineering). POSTECH University, Pohang.

Torrey, D. A., \& Al-Zamel, A. M. A. M. (1995, May). Single-phase active power filters for multiple nonlinear loads. IEEE Transactions on Power Electronics, 10(3), 263-272. doi:10.1109/ 63.387990

Tsang, K. M., \& Chan, W. L. (2006, September). Design of single-phase active power filter using analogue cascade controller. IEE Proceedings Electric Power Applications, 153(5), 735-741. 